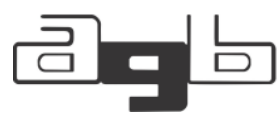

\title{
A IMPORTÂNCIA DA ATIVIDADE INTERATIVA NAS \\ AULAS SÍNCRONAS DE GEOGRAFIA: ANÁLISE DA \\ PRÁTICA REALIZADA EM UMA ESCOLA ESTADUAL DO \\ MUNICÍPIO DE POÇOS DE CALDAS, MINAS GERAIS
}

\author{
Bruna de Oliveira Ramos Garcia
}

Ana Carolina Siqueira da Fonseca ${ }^{2}$

Jennifer Valério Silva ${ }^{3}$

RESUMO: O presente artigo trata-se de uma proposta de atividade interativa online para o $8^{\circ}$ ano do ensino fundamental II da Escola Estadual Francisco Escobar, localizada na cidade de Poços de Caldas/MG, utilizando uma plataforma de aprendizado com jogos online e quiz (Kahoot!) para uma interação da turma sobre os conteúdos aprendidos. A atividade busca revisar de forma descontraída o conteúdo do Plano de Estudo Tutorado vol. 2, desenvolvido pela Secretaria de Estado de Educação de Minas Gerais, ofertado as escolas de rede pública como alternativa de continuidade do ensino durante o período de aulas remotas em decorrência da pandemia da Covid-19. Assim, o artigo fruto de uma prática com aulas remotas e um recurso como atrativo de interação dos discentes é apontando como uma importante prática pedagógica e lúdica para a relação entre o ensino e a aprendizagem para que ambas se tornem significativas.

PALAVRAS-CHAVE: Atividade Interativa; Proposta Pedagógica; Aprendizagem Significativa; Ensino de Geografia; Residência Pedagógica.

\section{THE IMPORTANCE OF INTERACTIVE ACTIVITY IN SYNCHRONOUS GEOGRAPHY CLASSES: ANALYSIS OF PRACTICE CARRIED OUT IN A STATE SCHOOL IN THE MUNICIPALITY OF POÇOS DE CALDAS, MINAS GERAIS}

\footnotetext{
${ }^{1}$ Graduando em Licenciatura em Geografia IFSULDEMINAS- Campus Poços de Caldas - e-mail: bruna.garcia@alunos.ifsuldeminas.edu.br

${ }^{2}$ Graduando em Licenciatura em Geografia IFSULDEMINAS - Campus Poços de Caldas - e-mail: ana.siqueira@alunos.ifsuldeminas.edu.br

3 Docente Preceptor, E. E. Francisco Escobar - Poços de Caldas. E-mail: jennifersjdr@yahoo.com.br
} 
ABSTRACT: This article is about an online interactive activity proposal for the 8 th grade of elementary school II at Francisco Escobar State School, located in the city of Poços de Caldas/MG, using a learning platform with online games and quiz (Kahoot!) for a class interaction about the learned content. The activity seeks to review the content of the Tutored Study Plan vol. 2, developed by the Minas Gerais State Department of Education, offering public schools as an alternative for continuing education during the period of remote classes as a result of the Covid-19 pandemic. Thus, the article, the result of a practice with remote classes and a resource as an attraction for students' interaction, is pointing out as an important pedagogical and playful practice for the relationship between teaching and learning so that both become meaningful.

KEYWORDS: Interactive Activity; Pedagogical Proposal; Meaningful Learning; Teaching of Geography; Pedagogical Residence.

\section{LA IMPORTANCIA DE LA ACTIVIDAD INTERACTIVA EN LAS CLASES DE GEOGRAFÍA SINCRÓNICA: ANÁLISIS DE LA PRÁCTICA REALIZADA EN UNA ESCUELA ESTATAL DEL MUNICIPIO DE POÇOS DE CALDAS, MINAS GERAIS}

RESUMEN: Este artículo trata sobre una propuesta de actividad interactiva en línea para el $8^{\circ}$ grado de la escuela primaria II en la Escuela Estatal Francisco Escobar, ubicada en la ciudad de Poços de Caldas / MG, utilizando una plataforma de aprendizaje con juegos y cuestionarios en línea (¡Kahoot!) Para una interacción en clase sobre el contenido aprendido. La actividad busca revisar el contenido del Plan de Estudios Tutorados vol. 2, desarrollado por el Departamento de Educación del Estado de Minas Gerais, que ofrece escuelas públicas como alternativa para la educación continua durante el período de clases remotas como resultado de la pandemia Covid-19. Así, el artículo, resultado de una práctica con clases a distancia y un recurso como atractivo para la interacción de los estudiantes, se apunta como una práctica pedagógica y lúdica importante para la relación entre la enseñanza y el aprendizaje para que ambos adquieran significado.

PALABRAS CLAVE: Actividad Interactiva; Propuesta Pedagógica; Aprendizaje Significativo; Enseñanza de la Geografía; Residencia Pedagogica.

\section{INTRODUÇÃO}

Com o regime de aulas remotas em todas as escolas públicas devido a pandemia da COVID-19 se fez necessária a adaptação para o formato online das aulas, sendo assíncronas ou síncronas as aulas em escolas estaduais, que 
tiveram como material de apoio o Plano de Estudo Tutorado, desenvolvido especialmente para este momento tão delicado que a educação passa em meio a pandemia.

O momento também exige dos professores novas formas de adaptar sua aula no ambiente virtual para que os alunos não percam o interesse, vide o aumento da evasão escolar por conta da pandemia que acarretou problemas na vida de todos. Sendo o trabalho do residente contribuir para o aprendizado do aluno, neste cenário atual, os professores preceptores da Residência Pedagógica viram a possibilidade da oferta de vídeos e podcasts, como materiais que revisam os conteúdos ao longo do semestre, estando também, sempre a disposição para a retirada de possíveis dúvidas.

A Residência Pedagógica é um programa da CAPES que tem por objetivo a formação prática de alunos de cursos de licenciatura, possibilitando a imersão destes na escola de educação básica; e, no ano de 2020, o Instituto Federal do Sul de Minas Gerais - Campus Poços de Caldas, passou a integrar este programa tendo a participação de 20 alunos divididos em duas instituições de ensino para que realizassem a prática docente.

Em razão da necessidade de aplicar novas práticas que adaptassem os conteúdos de maneira virtual e que ainda despertasse nos alunos o interesse de participar, a professora preceptora Jennifer Valério que acompanha o desenvolvimento dos residentes na Escola sugeriu que os alunos pensassem uma estratégia lúdica para o ensino dos conteúdos e foi assim que se viu no jogo Kahoot $!^{4}$ tal possiblilidade, pois além de ser interessante, ainda permite que 0 professor aplique um jogo online com questões elaboradas por ele próprio, levando em consideração o perfil da turma a ser aplicado o jogo.

\footnotetext{
${ }^{4}$ Kahoot! é um aplicativo norueguês fundado em 2012, com a função de construir jogos educativos como quizzes e outros jogos interativos, utilizados por professores para dinamizar os conteúdos aprendidos em sala de aula.
} 
Portanto, o jogo estar alinhado com o material que os alunos estão trabalhando nas aulas, é fundamental. O Kahoot! foi escolhido pois permite uma interação entre a turma através da pontuação de cada um e estimula o raciocínio, além de ser recreativo.

Deste modo, o objetivo desta atividade prática em aulas síncronas está em reforçar os conteúdos ofertados no segundo semestre de 2021 para o oitavo ano do ensino no período de aplicação desta atividade os alunos estão iniciando o PET (Plano de Estudo Tutorado) vol. 3, a atividade se dá como revisão.

\section{FUNDAMENTAÇÃO TEÓRICA}

Para aplicar o conteúdo proposto em sala de aula necessitamos de uma consulta na Base Nacional Comum Curricular (BNCC), pois ela atualmente busca nortear o trabalho a ser desenvolvido em sala de aula, além de estar presente no material didático fornecido aos alunos. A BNCC (2017, p. 360) nos diz que a contribuição da Geografia aos alunos da Educação Básica está em desenvolver o pensamento espacial, estimulando o raciocínio geográfico para representar e interpretar o mundo em permanente transformação e relacionando componentes da sociedade e da natureza. Desta forma, os conteúdos priorizados pela BNCC estão vinculados diretamente aos principais conceitos da Geografia contemporânea que mobilizem o pensamento espacial e, também, possibilitem ao estudante que domine outros conceitos do espaço geográfico como território, lugar, região, natureza e paisagem.

O Plano de Estudo Tutorado volume 2 que foi trabalhado ao longo do segundo bimestre com a turma de $8^{\circ}$ ano do Ensino Fundamental baseia-se nas unidades temáticas da BNCC que

destacam aspectos relacionados ao exercício da cidadania e à aplicação de conhecimentos da Geografia diante de situações e problemas da vida cotidiana, tais como: estabelecer regras de 
convivência na escola e na comunidade; discutir propostas de ampliação de espaços públicos; e propor ações de intervenção na realidade, tudo visando à melhoria da coletividade e do bem comum (BNCC, 2017, p. 364).

Para tanto, foi realizado um estudo mais aprofundado das temáticas apresentadas pela BNCC e também pelo PET oferecido aos alunos, para assim se pensar nas questões que fariam parte da atividade proposta. Tais conteúdos do $\mathrm{PET}^{5}$ volume 2 foram divididos em atividades de seis semanas, sendo a primeira delas sobre "O sujeito e seu lugar no mundo", visando a diversidade e dinâmica da população mundial e local como objeto do conhecimento e trabalhando conteúdos relacionados a dinâmica demográfica do país, estado e município; o município e suas características socioeconômicas, ambientais, políticas e culturais; população por idade e sexo (pirâmide etárias); indicadores sociais (MINAS GERAIS, 2021, p. 69).

A segunda, terceira e quarta semana trabalhou a temática de "Conexões e escalas", tendo a segunda semana enfoque dos objetos de conhecimento sobre as corporações e organismos internacionais e do Brasil na Ordem Econômica e Mundial, com conteúdos relacionados ao Estado, território, governo, nação e país; os conflitos contemporâneos a partir dos conceitos de estado, território, governo, nação e país; conflitos e tensões na América e na África (MINAS GERAIS, 2021, p. 74).

A terceira semana enfocou os objetos de conhecimento em relação às corporações e organismos internacionais e do Brasil na Ordem Econômica e Mundial, com o conteúdo relacionado às organizações mundiais (ONU, OMC, OTAN, FMI, OIT, OCDE e Banco Mundial); o papel das organizações mundiais na

\footnotetext{
${ }^{5}$ Os conteúdos disponibilizados nos PETs foram criados pela SEE conforme indicado pelo Currículo Referência de Minas Gerais (CRMG) e pela Base Nacional Comum Curricular (BNCC) para cada etapa de ensino. Cabe aos professores analisar os conteúdos e propor atividades para complementá-los.
} 
América e na África; o papel dos blocos econômicos na integração dos países do continente americano no cenário mundial (MINAS GERAIS, 2021, p. 79).

A quarta semana, por sua vez, teve enfoque nas corporações e organismos internacionais e do Brasil na Ordem Econômica e Mundial, trazendo conteúdos sobre Globalização/nova ordem mundial; meio técnico-científico informacional e os continentes americano e africano; identidades e interculturalidades regionais: Estados Unidos, América espanhola, portuguesa e África (MINAS GERAIS, 2021, p. 83).

A quinta semana traz como unidade temática "O mundo do trabalho", para falar sobre os diferentes contextos e os meios técnicos e tecnológicos na produção e, fornecendo aos alunos conhecimentos sobre Países latinoamericanos e os circuitos de produção agrícola e industrial; os setores da economia: primário, secundário e terciário; o mundo do trabalho na atualidade e seus reflexos na América e na África (MINAS GERAIS, 2021, p. 86).

Por último, a semana seis apresenta como unidade temática as "Formas de representação e pensamento espacial", em que se fala sobre cartografia: anamorfose, croquis e mapas temáticos da América e África. Os conteúdos desta unidade estão relacionados às diferentes formas de representação como mapas, gráficos e tabelas (MINAS GERAIS, 2021, p. 90).

De acordo com a BNCC (2017, p. 381), os anos finais do Ensino Fundamental, têm por objetivo "garantir a continuidade e a progressão das aprendizagens do Ensino Fundamental - Anos Iniciais em níveis crescentes de complexidade da compreensão conceitual a respeito da produção do espaço", ampliando os conhecimentos adquiridos anteriormente pelos alunos. No $8^{\circ}$ e o $9^{\circ}$ ano o enfoque do ensino concentra-se no espaço mundial, cabendo aos alunos compreender como a divisão internacional do trabalho e a distribuição da riqueza tornaram-se muito mais fluidas e complexas do ponto de vista das interações espaciais e das redes de interdependência em diferentes escalas 
(BRASIL, 2017, p. 382), aprendendo principalmente sobre as dimensões da política, da cultura e da economia no mundo. Para tanto,

explora-se, no $8^{\circ}$ ano, uma análise mais profunda dos conceitos de território e região, por meio dos estudos da América e da África. Pretende-se, com as possíveis análises, que os estudantes possam compreender a formação dos Estados Nacionais e as implicações na ocupação e nos usos do território americano e africano. As relações entre como ocorreram as ocupações e as formações territoriais dos países podem ser analisadas por meio de comparações, por exemplo, de países africanos com países latino-americanos, inserindo, nesse contexto, o processo socioeconômico brasileiro. Destaca-se também a relevância do estudo da América do Norte, com ênfase no papel dos Estados Unidos da América na economia do pós-guerra e em sua participação na geopolítica mundial na contemporaneidade. Nos estudos regionais, sejam da América, sejam da África, as informações geográficas são fundamentais para analisar geoespacialmente os dados econômicos, culturais e socioambientais - tais como GINI, IDH, saneamento básico, moradia, entre outros -, comparando-os com eventos de pequenas e grandes magnitudes, como terremotos, tsunamis e desmoronamentos devidos a chuvas intensas e falta da cobertura vegetal. Considera-se que os estudantes precisam conhecer as diferentes concepções dos usos dos territórios, tendo como referência diferentes contextos sociais, geopolíticos e ambientais, por meio de conceitos como classe social, modo de vida, paisagem e elementos físicos naturais, que contribuem para uma aprendizagem mais significativa, estimulando o entendimento das abordagens complexas da realidade, incluindo a leitura de representações cartográficas e a elaboração de mapas e croquis (BRASIL, 2017, p. 382-383).

Após analisar os conteúdos propostos pela Base Nacional Curricular Comum e também cada semana de atividades propostas pelo PET volume 2, entende-se que há uma grande necessidade de explorar práticas pedagógicas que possibilitem uma melhor interpretação dos alunos em relação ao que tem sido estudado e aprendido. E foi, no lúdico que encontrou-se tal possibilidade, pois este tipo de atividade no ensino de Geografia proporciona o prazer e 
divertimento durante as aulas, ao passo em que ajuda a desenvolver no educando habilidades cognitivas e motoras; atenção e percepção; capacidade de reflexão; conhecimento quanto à posição do corpo; direção a seguir e outras habilidades importantes para o desenvolvimento da pessoa humana, como colocado por Pinheiro, Santos e Ribeiro Filho no artigo "Brincar de Geografia: o lúdico no processo de ensino e aprendizagem" (2013, p. 27).

Entende-se, portanto, que:

[...] os jogos e as atividades lúdicas tornam-se significativas à medida que a criança se desenvolve, com a livre manipulação de materiais variados, ela passa a reconstituir e reinventar as coisas, que já exige uma adaptação mais completa. Essa adaptação só é possível, a partir do momento em que ela própria evolui internamente, transformando essas atividades lúdicas, que é o concreto da vida dela, em linguagem escrita que é o abstrato (PIAGET, 1975, p. 156 apud PINHEIRO, SANTOS, RIBEIRO FILHO, 2013, p. 27).

De acordo com Antunes (2006, p. 44, apud PINHEIRO, SANTOS, RIBEIRO FILHO, 2013, p. 29) no ensino de Geografia, os docentes podem se utilizar dos jogos que explorem as inteligências pessoais e a naturalista (ambiental), fazendo com que conheçam o espaço geográfico e construam conexões que permitam aos alunos perceber a ação do homem em sua transformação e em sua organização no espaço físico e social. Deste modo, a relação entre o ensino e a aprendizagem torna-se mais atrativa e, consequentemente, favorece o maior aproveitamento das aulas.

Partindo destas colocações, adotou-se como prática pedagógica o uso da atividade lúdica por meio do software Kahoot! que permite criar questionários que podem ser respondidos por usuários que estejam conectados à internet por meio de smartphones ou computadores (MARTINS, GERALDES, AFONSECA, GOUVEIA, 2018, p. 3). O jogo está totalmente dentro das referências que os alunos tiveram com seu material didático, e, portanto, a dificuldade não foi 
elevada e ainda promoveu questionamentos e comentários entre os alunos, proporcionando condições que os levassem a um melhor aprendizado.

\section{METODOLOGIA}

Após compreender a importância do uso de jogos e recursos pedagógicos para o ensino, adotou-se o uso do software Kahoot! para aplicação de uma atividade prática com a turma de $8^{\circ}$ ano do Ensino Fundamental da Escola Estadual Francisco Escobar ${ }^{6}$. A proposta é, por meio do jogo, evidenciar o que foi aprendido pelos alunos ao longo do segundo bimestre de 2021, em que foram trabalhados os conteúdos do PET volume 2 - as questões estão disponíveis no "anexo 1".

Para a construção e aplicação do jogo foi utilizado o método pedagógico construtivista, desenvolvido por Piaget e que busca estimular os estudantes para que eles construam seus próprios saberes (EDUCA+BRASIL), partindo de um material que eles já tinham conhecimento prévio e promovendo a interação de uns com os outros através do jogo, que não necessariamente era uma prova, servindo, portanto, como avaliação formativa onde a participação era mais importante do que a pontuação na nota final do aluno.

As questões dispostas no jogo são de múltipla escolha com alternativas que variam de acordo com o que é perguntado.

Com antecedência de uma semana os alunos foram avisados de que a próxima aula seria de um jogo e, dois dias antes, foi enviado aos alunos uma mensagem tutorial de como acessar o jogo, no entanto foi preciso reenviar o código para os alunos no horário e data da aula. Todos os alunos que se propuseram conseguiram acessar o jogo, tanto pelo celular quanto pelo computador. Após o jogo foi enviado um link do Google Meet pela professora no

\footnotetext{
${ }^{6}$ A E.E. Francisco Escobar foi fundada em 1996 pelo decreto $n$ 38.347, como junção entre duas escolas estaduais e, se situa na zona leste do município de Poços de Caldas MG.
} 
grupo de WhatsApp da turma, assim todos acessaram a sala e em uma aula dialogada fizeram seus comentários e tiraram suas dúvidas.

As questões intercalavam com as 6 semanas de atividades disponíveis no PET, sendo as questões 1 e 4 baseadas no conteúdo da primeira semana do PET volume 2, em que se trabalhou a "Diversidade e dinâmica da população mundial e local", com conteúdo relacionado a dinâmica demográfica do país, estado e município; o município e suas características socioeconômicas, ambientais, políticas e culturais; população por idade e sexo (pirâmides etárias); indicadores sociais (MINAS GERAIS, 2021, p. 69).

As questões 2, 3, 5 e 6 seguiram a semana 2 "Corporações e organismos internacionais e do Brasil na Ordem Econômica e Mundial", com o conteúdo voltado ao estudo de Estado, território, governo, nação e país; os conflitos contemporâneos a partir dos conceitos de estado, território, governo, nação e país; conflitos e tensões na América e na África (MINAS GERAIS, 2021, p. 74).

A questão 7 seguiu a semana 3, "Corporações e organismos internacionais e do Brasil na Ordem Econômica e Mundial" na qual os alunos estudaram sobre organizações mundiais (ONU, OMC, OTAN, FMI, OIT, OCDE e Banco Mundial); o papel das organizações mundiais na América e na África; o papel dos blocos econômicos na integração dos países do continente americano no cenário mundial (MINAS GERAIS, 2021, p. 79).

A questão 8, foi baseada na semana 5 do PET "Os diferentes contextos e os meios técnicos e tecnológicos na produção" na qual foi estudado sobre os países latino-americanos e os circuitos de produção agrícola e industrial. Os setores da economia: primário, secundário e terciário; o mundo do trabalho na atualidade e seus reflexos na América e na África (MINAS GERAIS, 2021, p. 86).

A questão 9, por sua vez, seguiu o conteúdo da semana 6 "Cartografia: anamorfose, croquis e mapas temáticos da América e África" em que se falou 
sobre diferentes formas de representações: (mapas, gráficos e tabelas) (MINAS GERAIS, 2021, p. 90).

Por último, a questão 10 se baseou na semana 4 "Corporações e organismos internacionais e do Brasil na Ordem Econômica e Mundial", onde viu-se sobre globalização/nova ordem mundial; meio técnico-científico informacional e os continentes americano e africano; identidades e interculturalidades regionais: Estados Unidos, América espanhola, portuguesa e África (MINAS GERAIS, 2021, p. 83).

\section{APLICAÇÃO}

No dia 19 de agosto, os alunos do $8^{\circ}$ ano do Ensino Fundamental da Escola Estadual Francisco Escobar, localizada no município de Poços de Caldas - MG, foram convidados a participar de uma atividade complementar na qual jogaram o jogo Kahoot!, um quiz com dez perguntas sobre o conteúdo aprendido no bimestre anterior.

O jogo estava sendo aplicado pela residente Ana Carolina e, no total, haviam 11 participantes, sendo um destes a professora de Geografia na escola, Jennifer Valério, e também, uma das residentes do programa Residência Pedagógica, Bruna, que estavam acompanhando e respondendo as questões junto dos alunos. Algumas imagens registradas no momento da aplicação estão disponíveis no "anexo 2".

\section{RESULTADOS E DISCUSSÕES}

Após a aplicação do quiz, os alunos foram convidados a uma reunião pelo Google Meet, onde se encerraria a aula síncrona. Ali os alunos puderam tirar dúvidas sobre as questões que consideraram mais difíceis e ver sua pontuação no jogo. 
Foi possível perceber uma grande interação da turma, já que muitos abriram o microfone para expor suas ideias. Além disso, viu-se que a aplicação de uma atividade lúdica, que insere os alunos em uma dinâmica como esta, de competição, ultrapassa o convencional e gera interação e entretenimento para todos.

Não foram todos os alunos que participaram, tendo um total de nove partícipes, pois a maioria que está no grupo do WhatsApp da matéria, não costuma acessar as aulas no geral. Porém o quórum que tivemos foi muito proveitoso e nos serviu de grande experiência esta aula, pois na pandemia, tudo o que tínhamos por certo foi alterado no momento em que percebemos que alguns alunos confundiram o código de acesso, assunto que foi tratado via grupo de WhatsApp e resolvido, enfatizando nosso lugar de estagiários, assumimos a responsabilidade de ajudar os alunos nas aulas remotas.

No "anexo 3" é possível verificar a lista de alunos participantes e suas pontuações, juntamente das perguntas e a quantidade de acertos gerada no relatório do jogo Kakoot!.

Neste momento nenhum aluno demonstrou constrangimento, pois eles mesmos queriam ver o resultado.

Em razão da quantidade mínima de alunos participantes no dia da aplicação, para a validação da atividade como complementar, a professora Jennifer Valério aplicará um formulário através do Google Forms (anexo 4) com as mesmas questões, com exceção das questões números 7 e 10, por opção da professora. Deste modo, os alunos poderão ser avaliados adequadamente e formalmente através do link enviado ao grupo de WhatsApp da turma.

As figuras escolhidas para as atividades foram comentadas pelos alunos, principalmente a questão 9, em que algumas alternativas eram parecidas propositalmente para gerar uma discussão entre os alunos, a questão continha a imagem de um mapa e de um drone tirando uma fotografia de um determinado 
local e o aluno deveria escolher entre as opções: "Aerofotogrametria"; "Sensoriamento Remoto"; "Cartografia"; "Sensoriamento Remoto" e "Aerofotogrametria e Cartografia." Sendo a correta a resposta "Aerofotogrametria e Sensoriamento remoto", não deixando as alternativas que continham um termo só totalmente erradas.

Para Pinheiro, Santos e Ribeiro Filho (2013), fazendo alusão à teoria piagetiana, em que discute a importância dos jogos para o aprendizado, pois através da questão propositalmente com palavras parecidas mas não sinônimos despertou a atenção dos alunos e todos aprenderam através da correção do jogo. E ainda assim, a maioria acertou esta questão, estando a 9 entre as mais bem respondidas (anexo 3) ou seja, o comentário de quem estava atenta ao jogo serviu para quem errou a questão. A partir daí a reunião via Google Meet seguiu para uma aula dialogada, na qual os alunos puderam tirar suas dúvidas com a professora. O Kahoot! "permite ensinar os alunos a aprender com mais prazer, a construir seus próprios conhecimentos e promover uma melhor comunicação; (...)" (MARTINS, 2018) e este encontro síncrono após o jogo foi essencial para que alcançássemos o aprendizado.

\section{CONSIDERAÇÕES FINAIS}

Em tempos de pandemia é importante lembrar o quão é importante o trabalho do professor, pois sem ele as aulas apenas com o material didático ficam monótonas e para evitar a evasão escolar é importante que se diversifique a aula, principalmente de Geografia pois alguns temas os alunos esquecem, sendo necessária uma revisão a cada vez que ele retorna. Por isso a atividade no kahoot! teve um caráter de revisão do conteúdo, podendo ser utilizado também como uma avaliação formativa ou simples recreação em que se aprende algo. Por ter uma interface intuitiva o Kahoot! É fácil para quem cria e para quem joga, podendo expandir as habilidades do professor ao criar o jogo e selecionar as 
questões. A aplicação descrita neste artigo teve um bom aproveitamento, pois a conversa remota depois nos aproximou pela primeira vez dos alunos, mesmo que não tenha ocorrido nenhum encontro presencial.

\section{REFERÊNCIAS BIBLIOGRÁFICAS}

BRASIL. Ministério da Educação. Base Nacional Comum Curricular. Brasília, 2017. MARTINS, Ernane Rosa et al. Uso do kahoot como ferramenta de aprendizagem. Goiás: Capsi 2018, 2018. 19 slides, color. Disponível em: https://bdigital.ufp.pt/bitstream/10284/6979/1/Slides\%20IFG\%20Kahoot.pdf. Acesso em: 10 ago. 2021.

MINAS GERAIS - Secretaria de Estado de Educação de Minas. Planos de Estudos Tutorados 2021. 2021. Estude em Casa. Disponível em: https://estudeemcasa.educacao.mg.gov.br/inicio. Acesso em: 10 ago. 2021.

PINHEIRO, Igor de Araújo; SANTOS, Valéria de Sousa; RIBEIRO FILHO, Francisco Gomes. BRINCAR DE GEOGRAFIA: o lúdico no processo de ensino e aprendizagem. Revista Equador (UFPI), Piauí, v. 2, n. 2, p. 25-41, jul. 2013. Disponível em: https://revistas.ufpi.br/index.php/equador/article/viewFile/1451/1159. Acesso em: 10 ago. 2021.

PROPOSTA Pedagógica Construtivista/Cognitivista. Educa+Brasil. Disponível em: https://www.educamaisbrasil.com.br/proposta-pedagogica/construtivistacognitivista. Acesso em: 08 dez. 2021. 


\section{ANEXOS}

\section{Anexo 1: Questões do Jogo}

1. Leia a alternativa e diga se é verdadeira ou falsa:

"China e Índia são os países mais populosos do mundo atualmente."

$x$ Verdadeira.

2. A qual conceito o trecho se refere?

“(...) grupo de pessoas que compartilham um passado histórico que deu origem a uma identidade cultural, ou seja, tem características comuns quanto ao idioma, costumes, língua, tradições e crenças. É um conceito definido, portanto, culturalmente."

\begin{tabular}{|l|l|}
\hline Estado & Território \\
\hline Nação & País \\
\hline
\end{tabular}

3. Qual o nome da ciência dentro da Geografia que estuda esses indicadores populacionais?

\begin{tabular}{|l|l|}
\hline Demografia & Cartografia \\
\hline Geologia & Climatologia \\
\hline
\end{tabular}

4. Leia a frase a seguir e diga se ela é verdadeira ou falsa.

“A imigração é o movimento de chegada de pessoas em um país estrangeiro, esses são os chamados imigrantes" 
$x$ Verdadeira

5. Em qual continente esses países ficam localizados?

HONDURAS

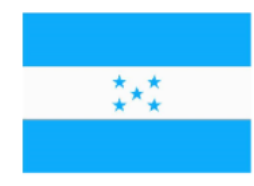

PANAMÁ

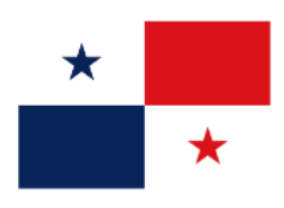

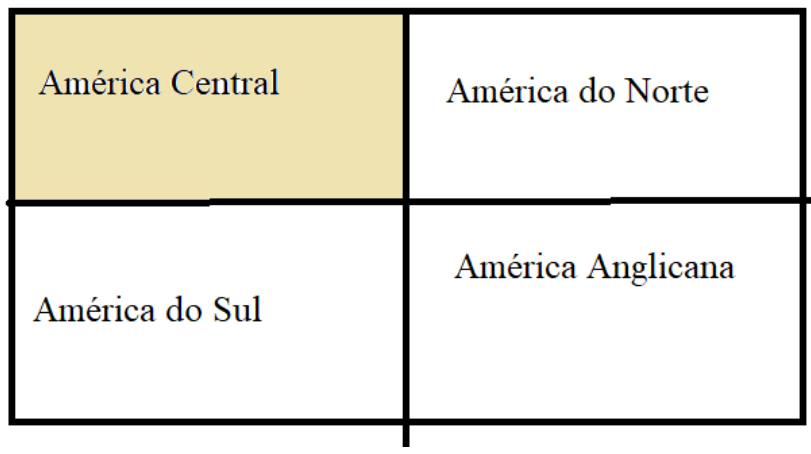

6.Neste mapa do continente africano é adotada uma divisão de duas regiões,

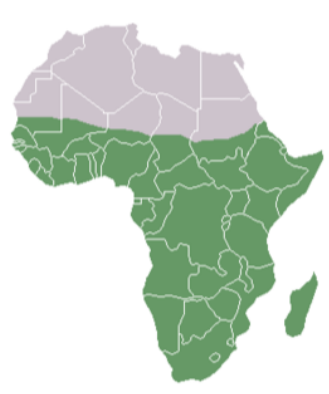

\begin{tabular}{|l|l|}
\hline $\begin{array}{l}\text { África do Norte e } \\
\text { Áfica do Sul }\end{array}$ & $\begin{array}{l}\text { África do Sul e África } \\
\text { Ocidental }\end{array}$ \\
\hline $\begin{array}{l}\text { África do deserto } \\
\text { e África Subsaariana }\end{array}$ & $\begin{array}{l}\text { África do Norte e África } \\
\text { Subsaariana }\end{array}$ \\
\hline
\end{tabular}

quais são elas?

7. Qual momento histórico de importância mundial o trecho faz referência?

“(...) iniciada logo após o fim da Segunda Guerra Mundial (1939-1945), polarizou o contraste ideológico entre o capitalismo e o socialismo, aprofundando um cenário de disputa internacional por novas tecnologias, armas nucleares, poder econômico, político e militar. A Queda do Muro de Berlim (1989) e o fim da União Soviética (1991) são fatos que simbolizaram seu fim."

Revolução comunista de 1917 na Rússia

Queda do muro de Berlim 
8. Verdadeiro ou Falso?

“Na primeira revolução industrial a descoberta do petróleo impulsionou as fábricas de tecido"

\section{$x$ Falso}
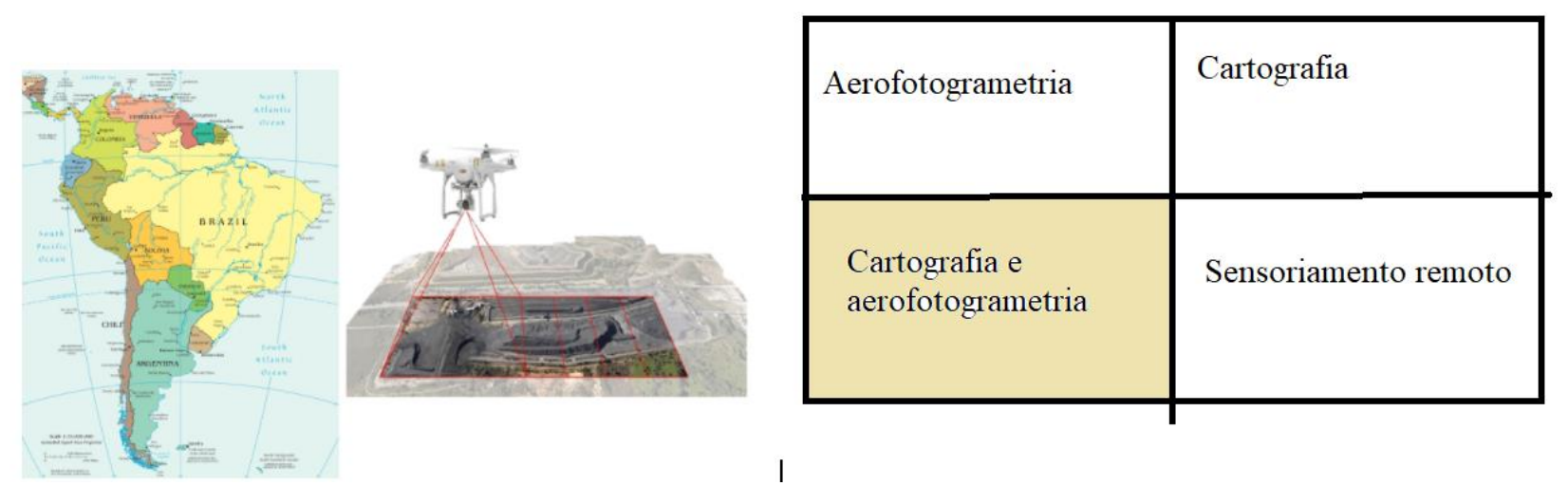

।

9. O que essas imagens representam?

10. A nova ordem econômica mundial pós Segunda Guerra Mundial definiu:

Países ricos e países pobres

$x$ Verdadeira 
Anexo 2: Aplicação do Jogo
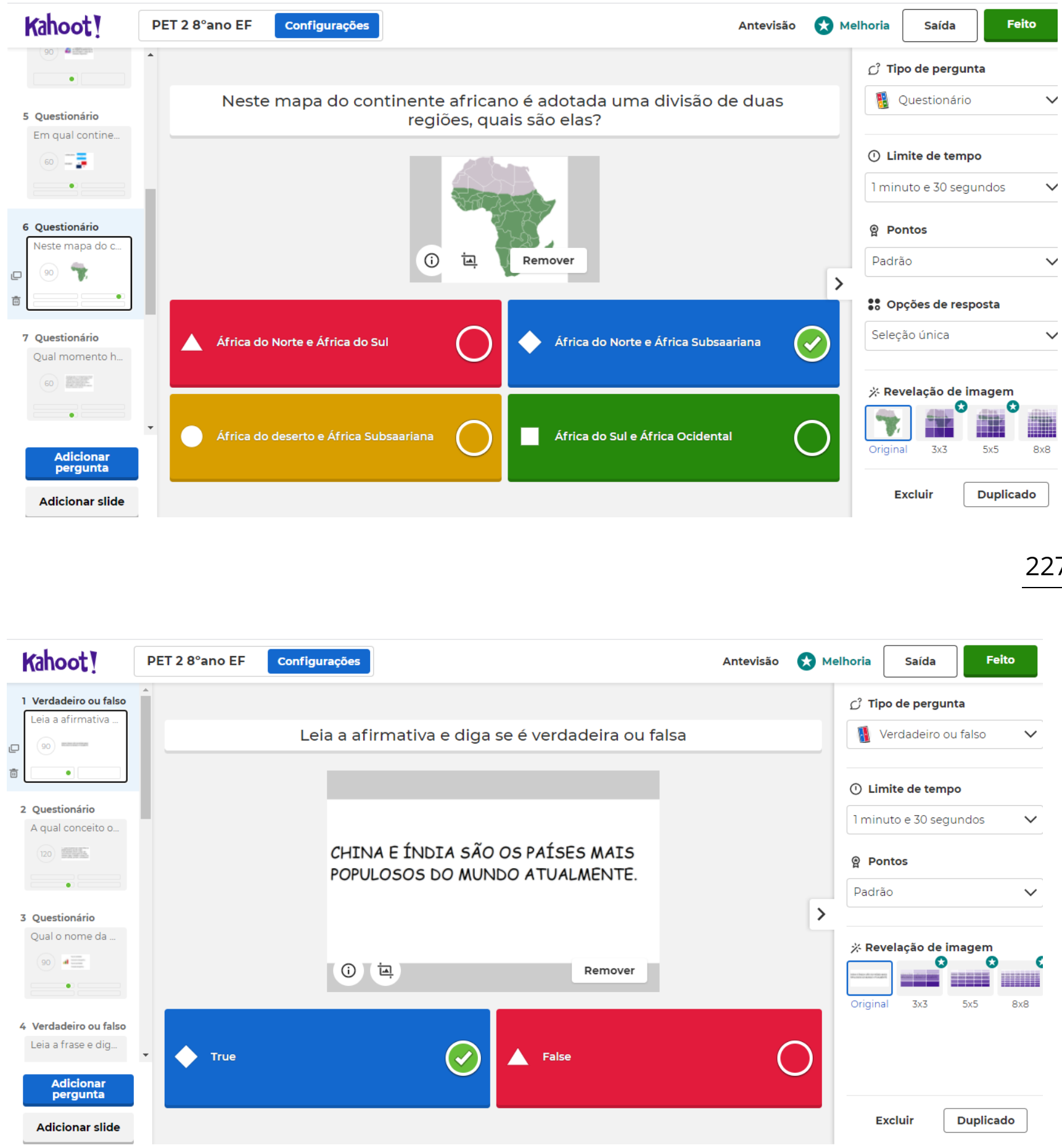
Anexo 3: Lista de Participantes e Pontuação

\begin{tabular}{lrrrr}
\hline Apelido & Classificação & Respostas corretas & Sem resposta & Pontuação final \\
\hline João mar... & 1 & $80 \%$ & 0 & 7667 \\
\hline Lorena & 2 & $70 \%$ & 0 & 5978 \\
\hline Delacroix & 3 & $70 \%$ & 3 & 5931 \\
\hline Yasmin & 4 & $60 \%$ & 0 & 5428 \\
\hline Paulo & 5 & $60 \%$ & 2 & 5188 \\
\hline Jerryan & 6 & $50 \%$ & 0 & 4715 \\
\hline Prof Jenni... & 7 & $50 \%$ & 5 & 4381 \\
\hline Sofia laura & 8 & $50 \%$ & 1 & 3989 \\
\hline Tassiany & 9 & $50 \%$ & 4 & 3752 \\
\hline carlos & 10 & $40 \%$ & 1 & 3031 \\
\hline Luan ..... & 11 & $30 \%$ & 2 & 2723 \\
\hline
\end{tabular}

Perguntas (10)

\begin{tabular}{rllr}
\hline \multicolumn{1}{l}{ Pergunta } & Modelo & Respostas corretas \\
\hline 1 & Leia a afirmativa e diga se é verdad ... & Verdadeiro o... & $40 \%$ \\
\hline
\end{tabular}

\begin{tabular}{cllc}
\hline 2 & A qual conceito o trecho de texto a... & Questionário & $26 \%$ \\
\hline 3 & Qual o nome da ciência da Geografi... & Questionário & $46 \%$ \\
\hline 4 & Leia uma frase e diga se ela é verda... & Verdadeiro o... & $60 \%$ \\
\hline 5 & Em qual países esses países ficam f... & Questionário & $46 \%$ \\
\hline 6 & Neste mapa do continente africano... & Questionário & $40 \%$ \\
\hline 7 & Qual momento histórico de import... & Questionário & $26 \%$ \\
\hline 8 & Verdadeiro ou Falso? & Verdadeiro o... & $26 \%$ \\
\hline 9 & O que essas imagens representam? & Questionário & $46 \%$ \\
\hline 10 & A nova ordem econômica mundial ... & Verdadeiro o... & $46 \%$ \\
\hline
\end{tabular}


Anexo 4: formulário - Google Forms

\section{$8^{\circ}$ Atividade Complementar PET3}

obrunah20@gmail.com Alternar conta

*Obrigatório

E-mail *

Seu e-mail

NOME *

Sua resposta

2) A qual conceito o trecho se refere? “(...) grupo de pessoas que compartilham um passado histórico que deu origem a uma identidade cultural, ou seja, tem características comuns quanto ao idioma, costumes, língua, tradições e crenças. É um conceito definido, portanto.

culturalmente."
Nação
Território
Pais
Estado 